\title{
Examining the effectiveness of initial response training program for nuclear emergency preparedness
}

\author{
S. Cha ${ }^{1,2}$, S.T. Kim ${ }^{1,3}$, S. Song,1, M.D. Yu¹, M. Pak¹, S. An¹, Y.W. Jin', \\ C. $\mathrm{Kim}^{2}$, M. Cho' ${ }^{*}$ \\ ${ }^{1}$ Korea Institute of Radiological \& Medical Science (KIRAMS), Seoul, South Korea \\ ${ }^{2}$ Department of Science \& Technology Policy (STP), Hanyang University, Seoul, South Korea \\ ${ }^{3}$ Nuclear Safety and Security Commission (NSSC), Seoul, South Korea \\ ${ }^{4}$ Department of Public Health Education, Kyunghee University, Gyeonggi-do, South Korea
}

\section{- Original article}

\section{*Corresponding authors: \\ Minsu Cho, Ph.D., \\ E-mail: choms@kirams.re.kr \\ Revised: November 2019 \\ Accepted: December 2019}

Int. J. Radiat. Res., October 2020; 18(4): $715-721$

DOI: 10.18869 /acadpub.ijrr.18.4.715

\begin{abstract}
Background: Although nuclear technology has various beneficial, it also has a variety of risks. In particular, initial response is very import to respond to risks. Therefore, the program to increase initial response proficiency can be regarded as very essential. The Republic of Korea annually conducts more than 10 nuclear emergency response training programs, and specialized training courses for initial response are conducted twice several times a year. Materials and Methods: The participants of the initial response training program were evaluated by senior professionals who had over 10 years of experience. The DISASTER Paradigm developed by the National Disaster Life Support Program was used as an index for evaluation. The purpose of evaluation was to identify issues in the current training program through evaluation results over a period of three years. The difference-in-differences method was used to quantitatively analyze the evaluation results. Results: Five indicators of the DISASTER Paradigm demonstrated that personnel skills improved through training. However, three indicators showed that skill levels decreased despite continued training. Conclusion: According to the results, the treatment of radioactive waste $(T)$, evacuation $(E)$, and triage of radiation exposure $(R)$ indicators showed a decrease in the proficiency level, which were difficult to demonstrate in the real world because of the specificity of radiation. Accordingly, program contents corresponding to $T, E$, and $R$ indicators must be revised using tools that can accurately portray the specificity of radiation.
\end{abstract}

Keywords: Nuclear emergency, initial response training, difference-in-differences method.

\section{INTRODUCTION}

Nuclear and radiation technology, which is one of the major sources of energy, is useful in medicine, non-destructive testing, well logging, and agriculture. Consequently, this technology is extremely crucial for national development and prosperity (1-3). However, nuclear accidents have the posibility of widespread of adverse effects. In particular, radiation causes biological effects and psychological fluctuations in the human body (4-5). Thus, a highly skilled expert must provide an early response during the occurrence of such accidents. Countries that are improving their nuclear technology and utilizing it in various fields are establishing nuclear emergency response planning programs in accordance with the international standards recommended by 
the International Atomic Energy Agency (6-7). As part of nuclear emergency preparedness, training programs have been implemented to improve the proficiency levels of agents. Several proficiency training programs have been implemented in the Republic of Korea (8). Among these programs, the initial response training program is the region of interest (ROI) of this research. For this purpose, a special team was established, and its members intensively participated in training programs for the improvement in proficiency levels concerning initial response. This study analyzes the efficacy of initial response training programs in improving personnel skills to respond to a nuclear accident. Accordingly, this study assesses the limitations of the current initial response training program and suggests directions for overcoming these limitations.

\section{MATERIALS AND METHODS}

\section{Initial response training program}

The Republic of Korea annually implements more than 10 nuclear emergency response training programs. Furthermore, several times of these training sessions focus on initial response training. Table 1 presents the types of training programs for nuclear emergency preparedness.

Minimizing the widespread impact of accidents through an accurate and prompt response during the early phases of a nuclear emergency is essential. In this study, " $\mathrm{H}$ " in table 1, which corresponds to the training during the early phase of a nuclear emergency, is designated as the ROI.

\section{Difference-in-differences method}

Government programs are implemented through the investment of public funds, which comprise social agreements and taxes collected from the citizens. Therefore, the public has the right to know if the program implemented by the government is efficient in accomplishing its intended purpose. Accordingly, the efficacy of the implemented program must be evaluated for public awareness. The evaluation results can be used as a foundation for making decisions concerning the effectiveness of the program or the continuation or discontinuation of its implementation. We used the difference-indifferences (DID) method, a frequently used research method in the social sciences, to evaluate the efficacy of the programs that have been implemented by the government. This method helped identify the contributions of the program toward achieving the goal because DID can deduce changes caused by external factors in addition to the effects of the program (6). Four factors were identified in this study: the response proficiency of the special team member before the implementation of the initial response training program, response proficiency of the special team member after the program implementation, non-special team member's response proficiency before the program implementation, and the non-special team member's response proficiency after the program implementation. The equation shown in table 2 was considered for the use of these four factors in the DID method.

In table 2, E0 indicates the proficiency level prior to program execution; E1 indicates the inhomogeneity between the two groups; d0 indicates the difference in proficiency levels due to inhomogeneity; $\mathrm{dE}$ indicates the rate of change in proficiency due to the program; and $\mathrm{dE}$ represents the observation target of this study.

\section{Quasi-experimental design}

The quasi-experimental design is frequently used in the social sciences, particularly the policy evaluation method. Through this method, participants can be easily obtained for experimental studies conducted in real-life settings. The reliability of the results of the social scientific experiment is high compared to that of the experimental design, as a quasi-experimental design is less likely to deviate from the selected group (experimental and control groups). However, the social scientific experiment has disadvantages, as it is not performed using a statistical random technique. Thus, a homogeneous group may be established. The quasi-experimental design was found to have a weak internal validity. Internal validity is one of

Int. J. Radiat. Res., Vol. 18 No. 4, October 2020 
the most fundamental properties of scientific studies and an essential concept in reasoning about evidence in more general terms (10). Despite its weak internal validity, the method can have high external validity and block the Hawthorne effect, a tendency for people to modify their behavior that results from their awareness of being observed (11). External validity is an important property of any study because general conclusions are a goal in

Table 1. Types of training programs for nuclear emergency preparedness.

\begin{tabular}{|c|c|}
\hline $\begin{array}{l}\text { Classification of } \\
\text { Training Program }\end{array}$ & Contents \\
\hline A & $\begin{array}{c}\text { A training program for improving the } \\
\text { proficiency in all response options } \\
\text { available to the government }\end{array}$ \\
\hline B & $\begin{array}{c}\text { A training program for increasing the } \\
\text { proficiency of responding systems of } \\
\text { the government, civilian, and armed } \\
\text { forces }\end{array}$ \\
\hline C & $\begin{array}{l}\text { Training programs for improving the } \\
\text { ability of nuclear business operators } \\
\text { to respond to nuclear emergency }\end{array}$ \\
\hline D & $\begin{array}{l}\text { Training programs for improving the } \\
\text { proficiency in specific areas, such as } \\
\text { radiation protection and radiation } \\
\text { emergency medicine field }\end{array}$ \\
\hline$E$ & $\begin{array}{l}\text { A training program for improving the } \\
\text { response to complex emergency } \\
\text { situations that can occur simultane- } \\
\text { ously with the nuclear emergency }\end{array}$ \\
\hline $\mathbf{F}$ & $\begin{array}{l}\text { Training programs for improving } \\
\text { proficiency in response to nuclear } \\
\text { emergency in neighboring countries } \\
\text { (Event corresponding to Emergency } \\
\text { Preparedness Category 5) }\end{array}$ \\
\hline G & $\begin{array}{l}\text { A training program for improving the } \\
\text { proficiency of responding to the use } \\
\text { of malicious nuclear technology for } \\
\text { terrorism purposes (Event } \\
\text { corresponding to Emergency } \\
\text { Preparedness Category 4) } \\
\end{array}$ \\
\hline H & $\begin{array}{l}\text { A training program for improving the } \\
\text { proficiency of responding quickly and } \\
\text { accurately to accidents in the early } \\
\text { phases of nuclear emergency }\end{array}$ \\
\hline
\end{tabular}

research (12).

\section{DISASTER paradigm}

The DISASTER Paradigm was developed by the National Disaster Life Support Program to evaluate the effectiveness of the training program in improving the proficiency levels of agents. The details of the DISASTER Paradigm are summarized in table 3 .

Table 2. Difference-in-differences equation ${ }^{(9)}$.

\begin{tabular}{|c|c|c|c|}
\hline & Experimental Group & Control Group \\
\hline \multirow{2}{*}{$\begin{array}{c}\text { Program } \\
\text { Execution }\end{array}$} & Before & $\mathrm{E} 0+\mathrm{E} 1$ & EO \\
\hline & After & $\mathrm{E} 0+\mathrm{E} 1+\mathrm{d} 0+\mathrm{dE}$ & $\mathrm{EO}+\mathrm{d} 0$ \\
\hline \multicolumn{2}{|c|}{ Rate of Change } & $\mathrm{d} 0+\mathrm{dE}$ & $\mathrm{d} 0$ \\
\hline \multicolumn{2}{|c|}{ Effectiveness } & \multicolumn{2}{|l|}{$\mathrm{dE}$} \\
\hline
\end{tabular}

Table 3. DISASTER Paradigm ${ }^{(13)}$.

\begin{tabular}{|c|c|c|}
\hline & Indicator & Contents of Details \\
\hline \multirow[b]{2}{*}{ D } & & Ability to identify accident information \\
\hline & Detection & $\begin{array}{c}\text { Cognitive abilities of accidents and } \\
\text { field conditions }\end{array}$ \\
\hline \multirow[b]{2}{*}{ I } & \multirow{2}{*}{$\begin{array}{c}\text { Incident } \\
\text { Management }\end{array}$} & $\begin{array}{l}\text { Ability to quickly switch to a response } \\
\text { system }\end{array}$ \\
\hline & & $\begin{array}{l}\text { Establishment of on-site emergency } \\
\text { operating system and ability to } \\
\text { perform roles }\end{array}$ \\
\hline \multirow{2}{*}{$\mathrm{S}$} & \multirow{2}{*}{$\begin{array}{l}\text { Safety and } \\
\text { Security }\end{array}$} & $\begin{array}{c}\text { Ability to maintain control over } \\
\text { patients, ability to carry out on-site } \\
\text { management }\end{array}$ \\
\hline & & $\begin{array}{l}\text { Ability to ensure the safety of injured } \\
\text { persons in disaster situation }\end{array}$ \\
\hline \multirow{2}{*}{ A } & \multirow{2}{*}{$\begin{array}{l}\text { Assess of } \\
\text { Hazards }\end{array}$} & $\begin{array}{l}\text { Ability to assess the risk factors that } \\
\text { may arise in responding to emergency }\end{array}$ \\
\hline & & $\begin{array}{c}\text { Ability to operate equipment for } \\
\text { emergency }\end{array}$ \\
\hline \multirow{2}{*}{$\mathrm{S}$} & \multirow{2}{*}{ Support } & $\begin{array}{l}\text { Ability to collaborate with designated } \\
\text { emergency institutions }\end{array}$ \\
\hline & & $\begin{array}{l}\text { Ability to use the walkie and radio } \\
\text { communication }\end{array}$ \\
\hline \multirow{2}{*}{$\mathrm{T}$} & \multirow{2}{*}{$\begin{array}{l}\text { Triage and } \\
\text { Treatment }\end{array}$} & $\begin{array}{c}\text { Ability of medical triage for injured } \\
\text { persons }\end{array}$ \\
\hline & & $\begin{array}{l}\text { Ability of radiological triage for } \\
\text { radiation injured persons }\end{array}$ \\
\hline \multirow{2}{*}{$\mathrm{E}$} & \multirow{2}{*}{ Evacuation } & $\begin{array}{l}\text { Ability to evacuate to areas for } \\
\text { minimizing radioactive contamination } \\
\text { and exposure }\end{array}$ \\
\hline & & $\begin{array}{l}\text { Ability to proceed with evacuation } \\
\text { procedures in areas where there is no } \\
\text { residence }\end{array}$ \\
\hline \multirow[b]{2}{*}{$\mathrm{R}$} & \multirow{2}{*}{ Recovery } & $\begin{array}{l}\text { Ability to manage and dispose of } \\
\text { radioactive waste }\end{array}$ \\
\hline & & $\begin{array}{l}\text { Ability to be quickly normalized by } \\
\text { routine work }\end{array}$ \\
\hline
\end{tabular}




\section{RESULTS}

To utilize the methodologies and tools introduced in the previous chapters, we have compiled raw data on the proficiency of response agents. The proficiency change data for 2016-2017 are summarized in table 4, and the proficiency change data for 2017-2018 are summarized in table 5 .

Table 4. 2016-2017 data for DID calculation.

\begin{tabular}{|c|c|c|c|c|c|c|c|c|}
\hline & D & I & S & A & S & T & E & R \\
\hline E0+E1+d0+dE & 793 & 711 & 702 & 734 & 729 & 750 & 704 & 694 \\
\hline$E 0+E 1$ & 418 & 401 & 379 & 403 & 427 & 452 & 425 & 473 \\
\hline$d 0+d E$ & 375 & 310 & 323 & 331 & 302 & 298 & 279 & 221 \\
\hline$E 0+d 0$ & 705 & 673 & 601 & 563 & 621 & 601 & 547 & 501 \\
\hline$E 0$ & 386 & 394 & 342 & 278 & 357 & 352 & 285 & 377 \\
\hline$d 0$ & 319 & 279 & 259 & 285 & 264 & 249 & 262 & 124 \\
\hline$d E$ & 56 & 31 & 64 & 46 & 38 & 49 & 17 & 97 \\
\hline
\end{tabular}

Table 5. 2017-2018 data for DID calculation.

\begin{tabular}{|c|c|c|c|c|c|c|c|c|}
\hline & D & I & S & A & S & T & E & R \\
\hline E0+E1+d0+dE & 810 & 732 & 711 & 740 & 731 & 761 & 723 & 702 \\
\hline$E 0+E 1$ & 435 & 422 & 388 & 409 & 429 & 463 & 444 & 481 \\
\hline$d 0+d E$ & 375 & 310 & 323 & 331 & 302 & 298 & 279 & 221 \\
\hline$E 0+d 0$ & 710 & 701 & 621 & 632 & 630 & 617 & 609 & 523 \\
\hline$E 0$ & 391 & 422 & 390 & 357 & 376 & 357 & 340 & 352 \\
\hline$d 0$ & 319 & 279 & 231 & 275 & 254 & 260 & 269 & 171 \\
\hline$d E$ & 65 & 65 & 92 & 56 & 48 & 38 & 10 & 50 \\
\hline
\end{tabular}

$\mathrm{E} 0+\mathrm{E} 1+\mathrm{d} 0+\mathrm{dE}$ can be expressed as the proficiency data for the group affected by the target program. Conversely, E0 $+\mathrm{d} 0$ can be expressed as the proficiency data for groups not affected by the target program. The difference in the proficiency of the experimental group before and after the program can be expressed as $\mathrm{d} 0+$ $\mathrm{dE}$. The difference in proficiency of the control group before and after the program execution can be expressed as d0. By subtracting the data from both groups, we can derive the net validity of the program or $\mathrm{dE}$. This calculation method is summarized in table 6 for each index of DISASTER Paradigm.
Table 5. 2017-2018 data for DID calculation.

\begin{tabular}{|c|c|c|c|}
\hline \multirow{2}{*}{\multicolumn{2}{|c|}{ DISASTER Paradigm }} & $\begin{array}{r}\text { Pure Effectiveness by } \\
\text { Program (Calculated by the } \\
\text { DID Method) }\end{array}$ \\
\cline { 3 - 4 } & & 56 & 65 \\
\hline D & Detection & 31 & 65 \\
\hline I & Incident Management & 64 & 92 \\
\hline S & Safety and Security & 64 & 2017-2018 \\
\hline A & Assess Hazards & 46 & 56 \\
\hline S & Support & 38 & 48 \\
\hline T & Triage and Treatment & 49 & 38 \\
\hline E & Evacuation & 17 & 10 \\
\hline R & Recovery & 97 & 50 \\
\hline
\end{tabular}

\section{DISCUSSION}

Figure 1 (D-Detection) shows a change in the ability to accurately analyze nuclear emergency. This (D-Detection) increased in proficiency level through the process of learning the classified nuclear emergency in the training program. In particular, (D-Detection) assessed whether agents could accurately interpret a hypothetical nuclear emergency scenario. As a result, as shown in figure 1, the training of agents increased their proficiency level.

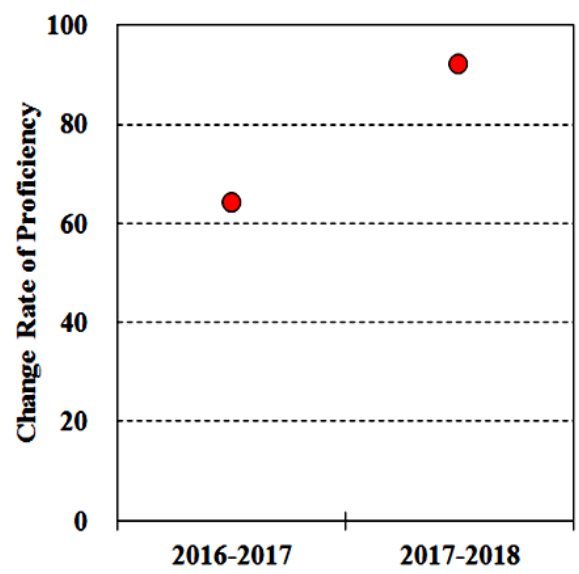

Figure 1. D (Detection) of the DISASTER Paradigm.

Figure 2 (I-Incident) shows a change in the ability to quickly switch to a system for responding to a nuclear emergency in normal 
situations and to operate the converted system. It was planned to increase the proficiency of agents through the process of actually deploying and operating on-site equipment in the training program. As a result, as shown in figure 2, the training of agents increased their proficiency level.

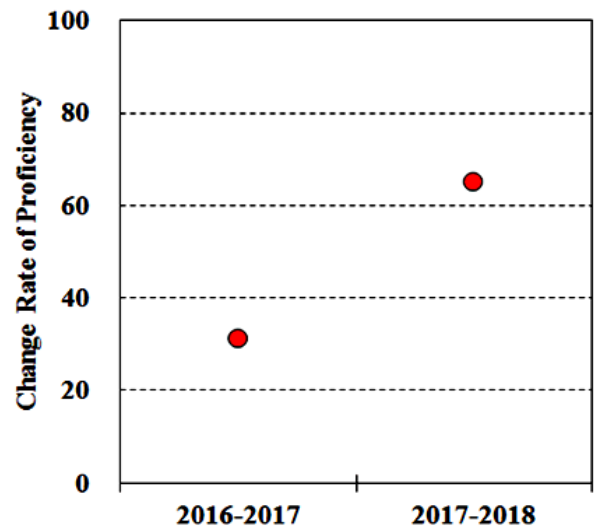

Figure 2. I (Incident) of the DISASTER Paradigm.

Figure 3 (S-Safety) shows a change in the ability of agents to ensure the safety of patients caused by an accident. It was planned to increase the proficiency of agents through the training of contents related to disaster medicine in the training program. As a result, as shown in figure 3 , the training of agents increased their proficiency level.

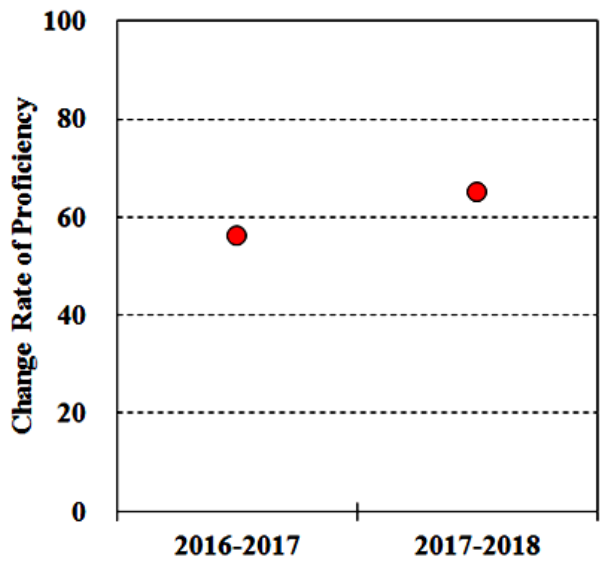

Figure 3. S (Safety) of the DISASTER Paradigm.

Figure 4 (A-Assessment) shows a change in the ability to identify the hazards at the site of the nuclear emergency and to operate the response equipment appropriately. It plans to Int. J. Radiat. Res., Vol. 18 No. 4, October 2020 increase the proficiency of agents through the education process that analyzes various disaster cases in addition to nuclear emergency cases. As a result, as shown in figure 4 , the training of agents increased their proficiency level.

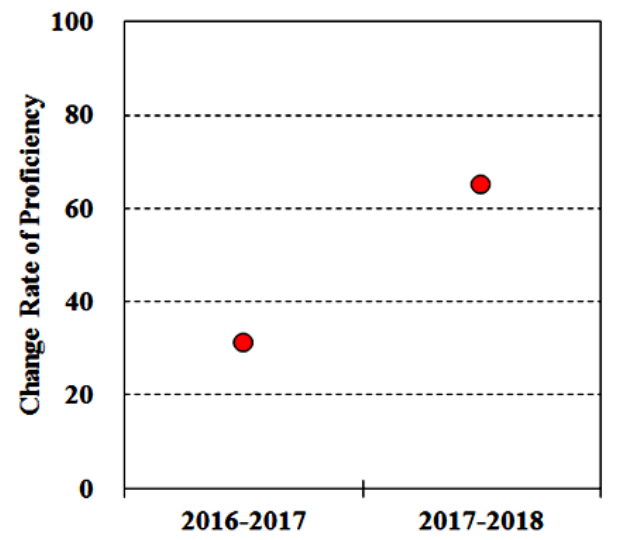

Figure 4. A (Assessment) of the DISASTER Paradigm.

Figure 5 (E-Evacuation) shows a change in the ability of agents to engage in remote communication and collaboration between various organizations to respond to nuclear emergency. This program was designed to increase the proficiency through the training process of inviting agents from other organizations to implement collaboration. As a result, as shown in figure 5, the training of agents increased their proficiency level.

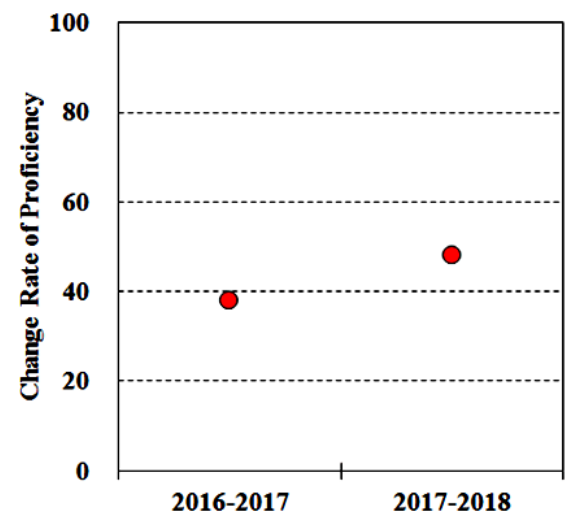

Figure 5. S (Support) of the DISASTER Paradigm.

Figure 6 (T-Triage) shows a change in the ability to classify and treat injuries caused by nuclear emergency. This (T-Triage) includes radiological triage and medical triage. In the case of medical triage, sufficient training could be 
conducted using educational tools like other medical facilities. Radiological triages, on the other hand, could not be practiced through descriptions similar to nuclear emergency in the real world of peace because of the specificity of radiation. As a result, as shown in figure 6, the training program did not increase the proficiency of agents.

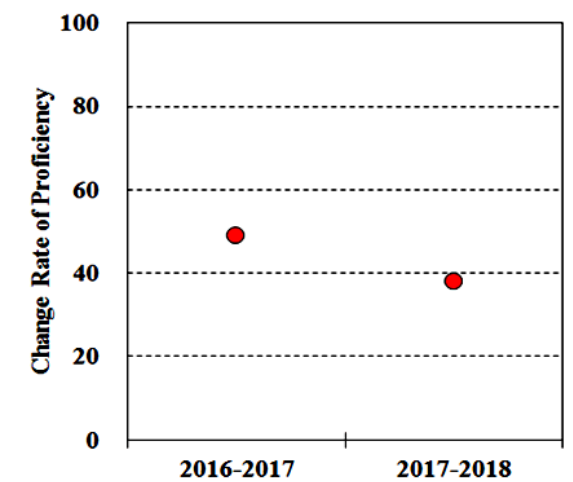

Figure 6. T (Triage) of the DISASTER Paradigm.

Figure 7 (E-Evacuation) shows the change in evacuating ability escaping from the radioactive contamination area. This (E-Evacuation) includes the ability to manage radiation exposure doses, especially in radioactive contamination area it also includes the ability to measure radioactive contamination on a wide range of lands, facilities and human bodies. This is the skill of specific behavior in a particular situation. And because of the specificity of radiation, it is impossible to describe the same situation as nuclear emergency in the real world of peace. As a result, as shown in figure 7, the training program did not increase the proficiency of agents.

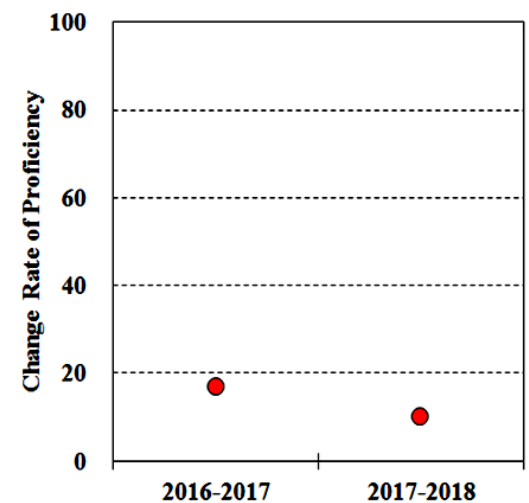

Figure 7. E (Evacuation) of the DISASTER Paradigm.
Figure 8 (R-Recovery) shows the change in capacity after the end of response to nuclear emergency, such as assessment, management and disposal of radioactive waste. In particular, there is a diversity and unpredictability of nuclear emergency situations. And, like figures 6 and 7 , this includes the specificity of radiation and the proficiency of specific behavior in particular situation. Therefore, as shown in figure 8 , the training program did not increase the proficiency of agents.

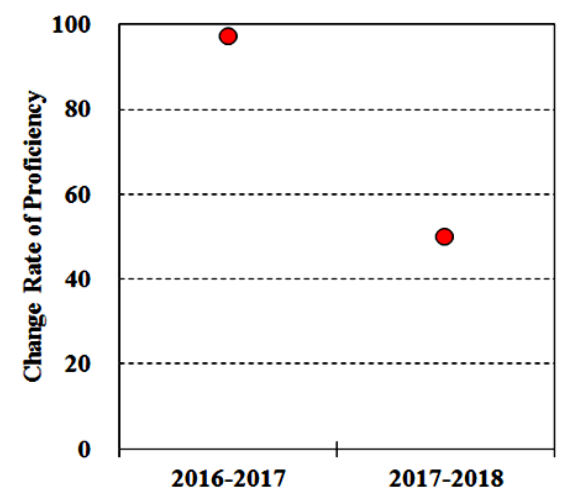

Figure 8. R (Recovery) of the DISASTER Paradigm.

The DID calculation results show that the top five indicators D, I, S, A, and S have achieved the purpose of the program. However, the bottom three indicators or $\mathrm{T}, \mathrm{E}$, and $\mathrm{R}$ indicate that the program did not achieve its goal. The characteristics of T, E, and R were proficiency in specific behaviors for special situations that are difficult to describe in the real world of peace.

\section{CONCLUSION}

The results of the present study suggest that the D, I, S, A, and S indicators were effective in training personnel and improving the proficiency levels of agents. The program contents of the five proven indicators were relatively easy in terms of determining the description of a nuclear emergency situation in the real world. However, the T, E, and R indicators showed a decrease in the proficiency level of agents. This result indicates that revisions are required to address the problems and limitations in the learning content of the $\mathrm{T}$,

Int. J. Radiat. Res., Vol. 18 No. 4, October 2020 
$\mathrm{E}$, and $\mathrm{R}$ indicators. These three indicators were difficult to reproduce in the real world during peacetime because of the specificity of radiation. Thus, innovative tools are essential to accurately describe the specificity of radiation in the real world. Artificial reality (AR) and virtual reality (VR) technologies are currently being used to increase the proficiency of stakeholders in safety -related fields (14). Currently, during the Fourth Industrial Revolution, various fields are introducing new AR and VR technologies to improve the proficiency of specific behaviors in special situations. In the medical field, particularly in the field of ophthalmology, which requires a high level of proficiency for specific behaviors, the improvement of proficiency using VR technology has been demonstrated (15). In mastoidectomy operations, which require a high level of specific behavioral skill in the medical field, the effectiveness of VR technology has been demonstrated (16). VR technology has already proved to be substantially useful in improving the proficiency of specific behaviors for escaping from narrow areas in special situations such as fires in certain areas such as mines (17). Therefore, this study recommends verifying the feasibility of using AR and VR technologies as part of the initial response training program for nuclear emergency preparedness for a follow-up study.

\section{ACKNOWLEDGEMENT}

This study was supported by a grant of the Korea Institute of Radiological and Medical Sciences (KIRAMS), funded by the Ministry of Science and ICT (MSIT), Republic of Korea. 50445-2020.

Conflicts of interest: Declared none.

\section{REFERENCES}

1. International Atomic Energy Agency [IAEA] (2006) Radiation and its role for health, environment and industrial development. Office of Nuclear Security, Namanga, Kenya.

2. International Atomic Energy Agency [IAEA] (2007) Radiation processing: Environmental applications. IAEA, Vienna.

3. Organization for Economic Co-operation and Development [OECD], Nuclear Energy Agency [NEA] (2012) The role of nuclear energy in a low-carbon energy future. OECD Publishing, Paris.

4. Thompson J (1986) Psychological consequences of disaster: Analogies for the nuclear case. National Academies Press, Washington, DC.

5. Salter CA (2001) Psychological effects of nuclear and radiological warfare. Mil Med, 166(12 Suppl): 17-18.

6. International Atomic Energy Agency [IAEA] (2007) Arrangements for preparedness for a nuclear or radiological emergency. Safety Guide No. GS-G-2.1. IAEA, Vienna.

7. International Atomic Energy Agency [IAEA] (2015) Preparedness and response for a nuclear or radiological emergency. General Safety Requirements No. GSR Part 7. IAEA, Vienna.

8. Nuclear and Radiological Emergency Monitoring Cell [NREMC] (2018) Nuclear emergency preparedness training assessment guidelines. NREMC, Republic of Korea.

9. Okurut JM (2018) Automatic promotion and student dropout: Evidence from Uganda, using propensity score in difference in differences model. J Educ Learn, 7(2): 191209.

10. Brewer M (2000) Research design and issues of validity. In: Handbook of Research Methods in Social and Personality Psychology, (Reis HT and Judd CM, eds.), Cambridge University Press, Cambridge.

11. McCarney R, Warner J, lliffe $S$, van Haselen R, Griffin $M$, Fisher $P$ (2007) The Hawthorne effect: A randomised, controlled trial. BMC Med Res Methodol, 7(30).

12. Pearl J and Bareinboim E (2014) External validity: From docalculus to transportability across populations. Stat Sci, 29 (4): 579-595.

13. Coule PL and Schwartz RB (2009) The national disaster life support programs: A model for competency-based standardized and locally relevant training. J Public Health Manag Pract, 15: S25-S3O.

14. Cakiroglu U and Gokoglu S (2019) Development of fire safety behavioral skills via virtual reality. Comput Educ, 133: 56-68.

15. Alwadani $\mathrm{F}$ and Morsi MS (2012) PixEye virtual reality training has the potential of enhancing proficiency of laser trabeculoplasty performed by medical students: A pilot study. Middle East Afr J of Ophthalmol, 19(1): 120-122.

16. Andersen SA (2016) Virtual reality simulation training of mastoidectomy: Studies on novice performance. Dan Med J, 63(8): pii: B5277.

17. Orr TJ, Mallett LG, Margolis KA (2009) Enhanced fire escape training for mine workers using virtual reality simulation. Min Eng, 61(11): 41-44. 
